Canadian

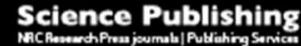

Canadian Journal of Microbiology Revue canadienne de de microbiologie

\title{
Diversity of endophytic and rhizoplane bacterial communities associated with exotic Spartina alterniflora and native mangrove using Illumina amplicon sequencing
}

\begin{tabular}{|r|l|}
\hline Journal: & Canadian Journal of Microbiology \\
\hline Manuscript ID: & cjm-2015-0079.R1 \\
\hline Manuscript Type: & Article \\
\hline Date Submitted by the Author: & 07-Jul-2015 \\
\hline Complete List of Authors: & $\begin{array}{l}\text { Hong, Youwei; Institute of Urban Environment, Chinese Academy of } \\
\text { Sciences, Urban ecological health and environmental security; University of } \\
\text { California, Riverside, Department of Environmental Sciences } \\
\text { Liao, Dan; Xiamen Huaxia Vocational College, Department of test of } \\
\text { science and technology } \\
\text { Hu, Anyi; Chinese Academy of Sciences, Institute of Urban Environment } \\
\text { Wang, Han; Wuyi University, College of Ecology and Resources Engineering } \\
\text { Chen, Jinsheng; Chinese Academy of Sciences, Institute of Urban } \\
\text { Environment } \\
\text { Khan, Sardar; University of Peshawar, Department of Environmental } \\
\text { Sciences } \\
\text { Su, Jian-Qiang; Institute of Urban Environment, } \\
\text { Li, Hu; University of Chinese Academy of Sciences, ; Chinese Academy of } \\
\text { Sciences, Institute of Urban Environment }\end{array}$ \\
\hline Keyword: & $\begin{array}{l}\text { Spartina alterniflora, mangrove, endophytic bacteria, diversity, Illumina } \\
\text { amplicon sequencing }\end{array}$ \\
\hline & \\
\hline
\end{tabular}




\section{Diversity of endophytic and rhizoplane bacterial communities}

2 associated with exotic Spartina alterniflora and native mangrove

$3 \quad$ using Illumina amplicon sequencing

4

5 Youwei Hong ${ }^{1,3}$, Dan $\mathrm{Liao}^{2}$, Anyi $\mathrm{Hu}^{1}$, Han Wang ${ }^{4}$, Jinsheng $\mathrm{Chen}^{1}$, Sardar Khan ${ }^{6}$, Jianqiang Su $6{ }^{1}, \mathrm{Hu} \mathrm{Li}^{1,5}$

7

$8 \quad{ }^{1}$ Key Laboratory of Urban Environment and Health, Institute of Urban Environment, Chinese

9 Academy of Sciences, Xiamen 361021, China

${ }^{2}$ Xiamen Huaxia Vocational College, Xiamen 361024, China

${ }^{3}$ Department of Environmental Sciences, University of California, Riverside, CA 92521 USA

${ }^{4}$ College of Ecology and Resources Engineering, Wuyi University, Wuyishan City 354300, China

${ }^{5}$ University of Chinese Academy of Sciences, Beijing 100049, China

${ }^{6}$ Department of Environmental Sciences, University of Peshawar, 25120, Pakistan

* Corresponding author: Youwei Hong (Ph.D)

Tel./fax: +86 5926190531

E-mail address: ywhong@iue.ac.cn; 


\section{Abstract}

Root-associated microbial communities are very important for biogeochemical cycles in wetland ecosystems and help to elaborate the mechanisms of plant invasions. In the estuary of Jiulong River (China), Spartina alterniflora has widely invaded Kandelia obovata-dominated habitats, which offers an opportunity to study the influence of root-associated bacteria. The community structures of endophytic and rhizophere bacteria associated with selected plant species were investigated using the barcoded Illumina paired-end sequencing technique. The diversity indices of root-associated bacteria in S. alterniflora were higher than the transition stands and K.obovata monoculture. Using principal coordinate analysis with UniFrac metrics, the comparison of $\beta$-diversity showed that all samples could be significantly clustered into three major groups, according to bacteria communities of origin. Four phyla, namely Proteobacteria, Bacteroidetes, Chloroflexi and Firmicutes, were enriched in the rhizoplane of both salt marsh plants, while they shared higher abundances of Cyanobacteria and Proteobacteria in endophytic bacteria. Phylum of Spirochaetes andChloroflexi were found in endophytic bacteria of S. alternifloraand K. obovata, respectively. One of the interesting findings was that endophytes were more sensitive response to plant invasion, compare to rhizophere bacteria. With linear discriminate analysis, we found some predominant rhizoplane and endophytic bacteria, including Methylococcales, Pseudoalteromonadacea,Clostridium, Vibrio and Desulfovibrio, which have the potential to affect the carbon, nitrogen and sulfur cycles. Thus, the results provide clues for the isolation of functional bacteria and the effects of root-associated microbial groups on S. alterniflora invasions.

Keywords: Spartina alterniflora; mangrove; endophytic bacteria; diversity; Illumina amplicon sequencing 


\section{Introduction}

Coastal wetland research has broadly focused on the preservation and restoration aspects, due to a range of ecosystem services such as carbon (C) sequestration and climate regulation (Hensel and Silliman 2013; Mcleod et al. 2011). In subtropical and tropical coastlines, mangroves are considered $\mathrm{C}$ rich ecosystems, and are beneficial to biodiversity, hydrology, and global biogeochemistry (Alongi 2014). However, the functions of mangrove ecosystems are increasingly threatening by human activities including eutrophication, organic and inorganic pollution, and the introduction of invasive species.

The invasion of exotic plant species may alter ecosystem functions through a variety of mechanisms such as reducing plant and animal biodiversity, altering wetland hydrology, and changing C or nitrogen (N) cycling(Williams and Grosholz 2008). Spartina alterniflora invasion affected the community structures of methanogens and sulfate-reducing bacteria in Phragmites australis-vegetated sediments (Zeleke et al. 2013). On the other hand, plants may benefit from association with diverse root-associated microbial communities which respond rapidly to environmental changes (Bai et al. 2013; Lau and Lennon 2012). The microbiota colonizing the rhizosplane and endophytic environment, contribute to plant growth, productivity, C sequestration and phytoremediation (Badri et al. 2009; Bulgarelli et al. 2012; Weyens et al. 2009). Biological interactions, including resource availability and enemy release, have been considered as the two common hypotheses of plant invasion mechanisms (Blumenthal et al., 2009).

The perennial salt marsh grass $S$. alterniflora, originated from the northeastern United States, was introduced to China in 1979. Due to its extensive expansion, S. alterniflora is widely distributed in nine coastal provinces in East and South China, while their displacement of the 
67

68

69

native species has caused a number of ecological impacts (Wan et al. 2009; Zhang et al. 2012).

Some studies investigated the effects of $S$. alterniflora invasion on mangrove ecosystems, including biomass of mangrove seedlings, macro-invertebrate communities, microeukaryotic diversity, and the composition of ammonia oxidizers (Yu et al. 2014; Zhang et al. 2012 \& 2013; Zhao et al. 2014). Rhizospheric bacterial diversity of $S$. alterniflora through denaturing gradient gel electrophoresis (DGGE) of PCR-amplified nifH gene or 16S rDNA fragments were also investigated (Lovell et al. 2000; Nie et al. 2010; Thomas et al. 2014). However, little attention has been paid to the bacterial diversity and structure of endophytic bacteria for both exotic and native plants (Debbab et al. 2013). Understanding community structures of root-associated bacteria from exotic plants would benefit to study their ecological functions and invasion mechanisms.

$$
\text { For analysis of microbial community structure, there are several previous }
$$
culture-independent methods, such as 16S rRNA gene clone libraries, terminal restriction fragment length polymorphism (TRFLP), and DGGE (Franco Dias et al. 2011; Theron and Cloete 2000; Zhang and Xu 2008). However, these molecular approaches could not reveal the details of the highly diverse microbial communities (Vanwonterghem et al. 2014; Zhang and Xu 2008). In recent years, pyrosequencing and Illumina techniques were widely used to get a more detailed picture of the microbial communities in various environment matrices (Degnan and Ochman 2012; Hu et al. 2014). Therefore, this study investigated the endophytic and rhizosplane bacterial community structure and diversity from three sampling stands covered by monocultures of $S$. alterniflora, Kandelia obovata and both plants (transition stands). These results would ultimately help in better understanding the potential impacts of $S$. alterniflora invasion on ecological function of mangrove. 
90

91

92

93

\section{Materials and Methods}

\section{Study sites and sampling}

Spartina alterniflora $(\mathrm{n}=6)$, Kandelia obovata $(\mathrm{n}=3)$ and sediment $(\mathrm{n}=9)$ samples were collected from Jiulong River Estuary Mangrove Nature Reserve $\left(24^{\circ} 24^{\prime} \mathrm{N}, 117^{\circ} 55^{\prime} \mathrm{E}\right)$, China, in July 2012. In the sampled habitat, 3 mangrove plant species including $K$. candel, Aegiceras corniculatum, and Avicennia marina were present. In 2007, S. alterniflora invaded the mudflat zone and the $K$. candel habitat, and then formed monoculture and transition zone in the low tidal wetland .The details of different types of samples are given in Table 1. For rhizosphere sediment (RS), roots of S.alterniflora and K.obovata were dug up and shaken gently, and then rinsed with saline water to remove the root adhering sediments. RS were stored into pre-cleaned brown glass bottles. The top 5-cm layer of the mudflat sediment (MS) was carefully placed into a bucket using a stainless steel spoon. All types of samples were taken in triplicates, and stored at $4{ }^{\circ} \mathrm{C}$ in car refrigerator (CF-110DC, WAECO, Germany), and then transported to the lab at the Institute of Urban Environment, CAS for further analyses. Physiochemical properties such as $\mathrm{pH}, \mathrm{TC}, \mathrm{TN}$ and TS of the sediment have already been reported in a previous study (Zhang et al. 2011). Sediment $\mathrm{pH}$ ranged from 6.12 to 6.99 units. TC and TN concentrations in the mudflat were 12.4 and $1.33 \mathrm{~g}$ $\mathrm{kg}^{-1}$, respectively, while in S. alterniflora zones were 12.4 and $1.49 \mathrm{~g} \mathrm{~kg}^{-1}$, respectively. These values were obviously lower than those (18.2 and $\left.1.81 \mathrm{~g} \mathrm{~kg}^{-1}\right)$ observed in native K.obovata zones.

Roots of S.alterniflora and K.obovata were thoroughly washed with deionized water, and rhizosplane bacteria were isolated by vigorously shaking of root segments (2 g) in $200 \mathrm{ml}$ of PBS 
110

111

112

113

114

115

116

117

118

119

120

121

122

123

124

125

126

127

128

129

130

131

buffer (140 mM NaCl, $2.5 \mathrm{mM} \mathrm{KCl}, 10 \mathrm{mM} \mathrm{Na} \mathrm{HPO}_{4}, 1.5 \mathrm{mM} \mathrm{KH_{2 }} \mathrm{PO}_{4}[\mathrm{pH}$ 7.4]) for $1 \mathrm{~h}$

(Mendes et al. 2007). Microbial cells were collected by centrifugation. Samples of endophytic

bacteria in roots were collected using the method adopted in our previous studies (Hong et al.,

2015). Briefly, washed root segments (5 g) were surface sterilized by sequential washing in $70 \%$

ethanol for $1 \mathrm{~min}$, sodium hypochlorite ( $2 \%$, vol $/ \mathrm{vol})$ for $3 \mathrm{~min}$, and $70 \%$ ethanol for $30 \mathrm{~s}$ and five

rinses with ample sterilized distilled water. Coated onto tryptic soy agar plates, the final rinse was used to verify surface sterilization. Plates were incubated at $28^{\circ} \mathrm{C}$, and no colonies were found after 10 days.

\section{DNA extraction, PCR and Illumina amplicon sequencing}

Surface-sterilized root segments were ground in a mortar with liquid nitrogen. Total DNA from sediment and strains was extracted and purified according to the manufacturer's recommendation, using the Fast DNA spin kit for soil (MP Biomedicals, California, USA) and the DNA purification kit (Tiangen, China). The V3 region of bacterial 16S rRNA gene was amplified $\begin{array}{lll}\text { using } & \text { 338F } & \text { (5'-ACTCCTACGGGAGGCAGCAG-3' }{ }^{\prime} \text { and }\end{array}$ (5'-TTACCGCGGCTGCTGGCAC-3') with identified barcodes (Huse et al. 2008). PCR amplifications were performed using a thermocycler (Eppendorf, Hamburg, Germany) in $50 \mu \mathrm{L}$ reaction volumes containing $25 \mu \mathrm{L}$ DreamTaq Green PCR Master Mix (2×) (Thermo Scientific Co., USA), $0.5 \mu \mathrm{L}$ of $1 \%$ bovine serum albumin (BSA), $0.2 \mu \mathrm{M}$ of each primer, $40-50$ ngof template DNA and $20.5 \mu \mathrm{L}$ of sterile water. PCR was carried out with the following temperature profiles: step one heated to $94{ }^{\circ} \mathrm{C}(3 \mathrm{~min}), 30 \mathrm{~s}$ of denaturation at $94{ }^{\circ} \mathrm{C}, 30 \mathrm{~s}$ at the primers annealing temperature $\left(55^{\circ} \mathrm{C}\right), 30 \mathrm{~s}$ of elongation at $72{ }^{\circ} \mathrm{C}$. PCR products were purified using a UniversalDNA purification kit (Tiangen, China) following the instructions of the manufacturer. 
132

133

134

135

136

137

The PCR productsfrom all samples were combined and stood in $0.1 \mathrm{vol} 3 \mathrm{~mol} / \mathrm{L}$ sodium acetate and 3 vol 100\% ethanol overnight. The pellet of combined DNAwas collected by centrifugation, washed with $75 \%$ ethanol, eluted in $50 \mu \mathrm{L}$ water and submitted to BGI (Beijing Genomics Institute, Shenzhen,China) for sequencing (pair-end) on Illumina HiSeq 2000 platform. Duplicates in endophytic bacteria of $K$. obovata (EBM) were only included in the Figure 3 data set due to sample loss.

\section{Data processing and statistical analysis}

The raw reads were assembled following the barcoded Illumina PE sequencing (BIPES) pipeline to reduce sequence and PCR errors (Zhou et al. 2011) and filtered by BGI in a pre-bioinformatics analysis. All the sequences were analyzed using QuantitativeInsights Into Microbial Ecology (QIIME, version 1.60) (Caporaso et al. 2010). As mentioned in previous studies (Xie et al., 2014), briefly, operational taxonomic units (OTUs) were picked at 97\% sequence similarity, and their representative sequences were chosen for alignment and taxonomic assignment with RDP classifier. Chimeric sequences, mitochondrial, chloroplast and singleton

OTUs were removed. We used phylogenetic diversity index (Phylogenetic Diversity (PD)), Shannon diversity index (H'), and an abundance-based coverage estimators Chaol as measures of $\alpha$-diversity according to our previous study (Hu et al. 2014). Rarefaction analysis, $\alpha$-diversity and $\beta$-diversity were conducted according to the OTU table with minimal sequencing number $(24,270)$ of the samples. For $\beta$-diversity analysis, dissimilarity of bacterial communities was determined using principal coordinate analysis (PCoA) on unweighted and weighted UniFrac distances among all samples. Venn diagrams were employed to characterize the shared bacterial communities among sample groups and to generate core microbiome in different samples. Linear discriminate 
154

155

156

analysis (LDA) effect size (LEfSe) was employed to identify indicator taxa (from genus to phylum level) associated with different sampling groups (Hu et al. 2014; Segata et al. 2011). All the sequences were uploaded to the NCBI SRA database under the accession number SRX525654.

Mean and standard deviation for each set of data were calculated. One-way analysis of variance (ANOVA) and least significant difference (LSD) were performed by SPSS (version 19.0) for Windows (IBM Co., USA), and the diversity of endophytic, rhizoplane and rhizophere bacteria from different wetland plants were compared.

\section{Results and Discussion}

\section{Diversity of endophytic and rhizoplane bacterial communities}

A total of 1,362,696 high-quality reads were obtained from 27 samples, and clustered into 44,094 OTUs at equal sequencing depth. RS samples presented the highest diversity of OTUs followed by MS, rhizoplane and endophytic bacteria. (Table 2). Alpha diversity using phylogeny-based metrics (PD) showed the significant difference between sediment and root-associated samples (ANOVA test, $\mathrm{P}<0.01$ ). The root itself is generally considered as a more stable niche, while RS represents more complex habitats providing microorganisms with a large variety of $\mathrm{C}$ sources, including amino acids, organic acids and carbohydrates etc. (Berg and Smalla 2009). In this study, diversity indices (Chao1 and Shannon) indicated higher diversity of rhizoplane and endophytic bacteria in the S. alterniflora monoculture compared with the K.obovatastands (ANOVA test, $\mathrm{P}<0.05$ ) (Table 2 and Fig.1).After S. alterniflora invasion, the diversity indices of its root-associated bacterial community decreased by approximately $20 \%$, due to the interactions between exotic and native plants to a certain extent. Blumenthal et al (2009) 
175

176

177

178

179

180

181

182

183

184

185

186

187

188

189

190

191

192

193

194

195

reported that plants classified as competitors hosted more than 4 times as many viruses and fungi as did stress tolerators. It also suggested that enemy release primarily contributes to invasion by fast-growing species adapted to resource-rich environments. In addition, the numbers of OTUs from the two rhizosphere sediments (RSSA and RSSAM) were higher than that in MS, indicating the "rhizosphere effect". Root exudates released from the exotic plants might cause changes in sediment parameters such as $\mathrm{pH}, \mathrm{C}, \mathrm{N}$ and $\mathrm{S}$ which significantly shaping rhizospheric bacterial community structure (Berg and Smalla 2009; Haichar et al. 2008; Zhang et al. 2011).

\section{Overlapping of OTUs}

According to the results of Venn analysis, consistent overlap patterns of OTU clusters among different samples were obtained (Fig.2). For endophytic bacteria, EBSA and EBSAM harbored 4,795 and 2,905 unique OTUs, respectively, while sharing250 and 612 OTUs with EBM. Moreover, EBM shared a large number of OTUs with EBSAM than EBSA. The results indicated the potential impact of Kobovata on the colonization of endophytic bacteria in roots of $S$. alterniflora. A similar variation pattern was observed for rhizoplane bacteria (Fig.2). These findings could be corroborated by the decreasing diversity indices of root-associated bacteria of $S$. alterniflora after its invasions. In comparison with MS, RSSA and RSSAM had higher OTUs overlap, which suggested the impact of plantation on the microbial community structure in the sediments. Sediment and rhizoplane bacterial communities had shown higher OTUs overlap as compared to those existing between endophytic and rhizoplane samples. Meanwhile, endophytic bacterial communities shared 4434 OTUs with rhizoplane and sediment samples, suggesting the colonization of endophyte in root partly originated from rhizopheric sediment environment. 
196

197

198

199

200

201

202

203

204

205

206

207

\section{Structure of bacterial communities}

Ordination plots based on PCoA analyses were constructed using unweighted and weighted UniFrac distances to identify the pattern of community structure of endophyte, rhizoplane and sediment bacteria (Fig. 3). RS and MS samples grouped tightly, and endophytic bacteria could be separated into two lineages; one included $K$. obovata samples, while the other group consisted on monocultures of $S$. alterniflora and transition stands. Rhizoplane bacteria from monocultures of $S$. alterniflora, $K$. obovata and transition stands were also grouped. Rhizoplane samples of $S$. alterniflora were closer to that of K.obovata, indicating the major influence of sediment properties. However, there were obvious difference in endophytic bacteria betweenS. alterniflora and K.obovata. This may be related to the difference between salt marsh plants. The result also showed the difference of endophyte and rhizoplane bacteria in the monoculture and transition stands of $S$. alterniflora, due to the influence of K.obovata (Fig.3). Overall, the clustered patterns of all samples were consistent with the OTUs and alpha analysis results.

\section{Taxonomic characteristics}

All representative sequences clustered into different groups (phyla or classes) according to the taxonomic classification of the EzTaxon-e database (Fig.4). In this study, 12 known phyla with a predominance of five major phyla (Proteobacteria, Cyanobacteria, Bacteroidetes, Firmicutes and Chloroflexi) were observed. It is obvious that Proteobacteria was the predominant phylum and contributed to $41-88 \%$ of the total tags. These results suggested high bacterial diversity across the rhizosphere, rhizoplane, endophyte of $S$. alterniflora and $K$. obovata. The number of phylum 
217

218

observed here was much greater than those reported inprevious studies using the 16S rRNA clone library (Li et al. 2014).

In S. alterniflora monoculture, major phyla of rhizoplane bacteria were Proteobacteria

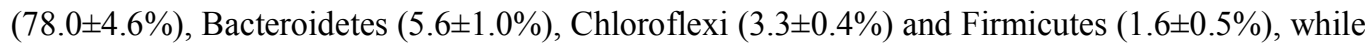

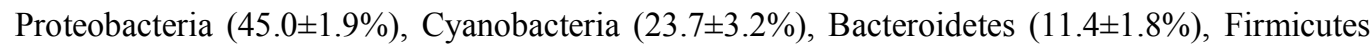
$(4.3 \pm 1.5 \%)$ and Spirochaetes $(4.1 \pm 0.6 \%)$ were predominant in their endophytic bacteria of roots (Fig.4). In contrast, dominant phyla in rhizoplane bacterial community of K.obovataincluded Proteobacteria $(88.0 \pm 7.7 \%)$, Bacteroidetes $(2.1 \pm 0.5 \%)$, Chloroflexi $(2.0 \pm 0.3 \%)$ and Firmicutes $(1.1 \pm 0.2 \%)$, while most of endophytic bacteria belong to Cyanobacteria (46.9 $\pm 1.2 \%)$, Proteobacteria $(41.7 \pm 6.3 \%)$, Firmicutes $(6.7 \pm 4.5 \%)$ and Chloroflexi $(1.1 \pm 0.8 \%)$. The results indicated that Cyanobacteria phylum was largely enriched in endophytic bacterial communities of both plants, while Spirochaetes only existed in S. alterniflora. The invasion and growth of $S$. alterniflora within K.obovata forest may increased the percentage of Cyanobacteria and decreased the abundance of Bacteroidetes in rhizoplane and endophytic bacteria. For the abundance of Cyanobacteria,a significant difference $(\mathrm{p}<0.001)$ was observed between EBSA and EBSAM, suggesting the influence of $S$. alterniflora invasion on the abundance of endophytic bacterial communities. This is possibly attributed to the impact of $K$. obovata stands, including root exudates, rhizophere bacteria, and the properties of sediments. Previous studies suggested the composition and temporal variation of soil microbial communities were associated with habitat characteristics and vegetation types, such as the influence of root exudates (Jiang et al. 2013; Lau and Lennon 2012). Meanwhile, soil type and host genotype also determined the composition of root-inhabiting bacterial communities, especially for soil-derived root endophytes (Badri et al. 
2009; Bulgarelli et al. 2012; Reinhold-Hurek and Hurek 2011).In this study, compared with MS, the abundances of Proteobacteria and Bacteroidetes in RSwere enhanced while numbers of Chloroflexi were inhibited. However, RS showed no difference of bacterial communities between S. alterniflora monoculture and its ecotone with K.obovata, mainly including Proteobacteria (55.7 $\pm 4.0 \%$ ), Chloroflexi (10.3 $\pm 1.4 \%)$, Bacteroidetes $(4.7 \pm 0.3 \%)$ and Firmicutes $(2.0 \pm 0.3 \%)$. It suggested more sensitive response of endophytes to environment change, compare to rhizophere bacteria (Bulgarelli et al. 2012). These limited samples reflect the variation of typical bacterial species in roots of the two plants, but we recommend that more samples be collected to identify the interactions of root-associated bacteria between different plants.

At the class level, $\alpha$-proteobacteria, $\delta$-proteobacteria and $\gamma$-proteobacteria were the major groups for all samples (Fig. 4). In the S. alterniflora monoculture, $\gamma$-proteobacteria $(52.2 \pm 4.6 \%)$ was significantly more prominent in rhizoplane bacteria, followed by $\delta$-proteobacteria $(15.9 \pm 0.2 \%)$ and $\alpha$-proteobacteria $(6.9 \pm 1.3 \%)$. In contrast, there were different pattern of endophytic bacteria, showing the distribution of $\delta$-proteobacteria $(16.4 \pm 1.9 \%)$, $\gamma$-proteobacteria $(13.5 \pm 1.0 \%)$ and $\alpha$-proteobacteria $(12.1 \pm 1.3 \%)$. In the transition stands, $\alpha$-proteobacteria, $\gamma$-proteobacteriaand $\delta$-proteobacteria in endophytic bacteria of $S$. alterniflora accounted for $23.0 \pm 5.4,8.9 \pm 0.6$ and $8.2 \pm 1.4 \%$, respectively. In addition, $\delta$-proteobacteria and $\gamma$-proteobacteria were greatly enriched in sediment samples with plantations, although there were no obvious difference for $\alpha$-proteobacteria between RS and MS.

\section{Indicator bacterial taxa and their ecological functional implication}

In addition to $\alpha$ - and $\beta$-diversity, LEfSe was used to demonstrate potentially discriminating 
260

261

262

263

264

265

266

267

268

taxa among three major habitats, including S. alterniflora and K.obovata stands (Fig.5). There were only three replicates for rhizoplane bacteria, therefore, we combined LDA score of exotic and native plants to determine their difference with other bacterial groups. The results showed that there were 33 taxa (4 phyla, 9 classes, 12 orders, 11 families, and 7 genera) distinguishing the two groups based on LDA scores $>3.0$. Phylum Proteobacteria and several $\gamma$-proteobacteria-associated taxa were significantly predominant in root-associated bacteria of S. alterniflora and K.obovata (RB group). For endophytic bacterial community in the roots of S. alterniflora, Bacteroideteswere enriched from different classified levels, such asBacteroidia, Flavobacteria and Sphingobacteriia. In addition, EBSA contained greater abundance of $\alpha$-proteobacteria (Proteobacteria), Clostridia (Firmicutes), Spirochaetes (Spirochaetes) and several taxa of $\delta$-proteobacteria than those in other groups. In comparison, Phylum Firmicutes were significantly more prominent the endophytic bacterial community in the roots of K.obovata, including Clostridiaceae, Pseudoalteromonadaceae, Oceanospirillaceae and Planococcaceae. However, Proteobacteria was enriched in the rhizoplane bacterial community in root of both plants.

Ecological functional implications of root-associated bacteria of $S$. alterniflora and K.obovatawere discussed in this study. In past, some studies reported that invasion of $S$. alterniflora would alter the community structure of related functional microorganisms, and affect the C, N and S cycles in the salt marshes ecosystem (Liao et al. 2007; Thomas et al., 2014). In this study, the community structure of rhizoplane and endophyte were investigated using samples from different stands covered by S. alterniflora and K.obovata (Fig.5), so as to further understand their impacts on natural ecology of salt marsh.

Nitrogen-fixation cyanobacteria are able to form symbiotic associations with various plants, 
282

283

284

285

286

287

288

289

290

291

292

293

294

295

296

297

such as wheat and potato (Gantar et al. 1995; Ringelberg et al. 2012). Fuernkranz et al. (2008) also reported that leaf-associated diazotrophic bacterial communities primarily belongs to Cyanobacteria, which may provide significant $\mathrm{N}$ input into this rainforest ecosystem. In this study, Cyanobacteria presence in root endophytes is valuable for the two plants to incorporate $\mathrm{N}$ into plant biomass. These results indicated that endophytic bacteria from these salt marsh plants may provide an advantage as $\mathrm{N}$-fixer agents. We also found the genus Clostridium, which is considered a ubiquitous endophytic bacterium in gramineous plants and has exhibited $\mathrm{N}_{2}$-fixing capability in association with nondiazotrophic endophytes (Miyamoto et al. 2004). Nitrogen-fixing bacteria have been isolated from mangrove rhizosphere and were identified as members of the genera Azospirillum, Azotobacter, Rhizobium, Klebsiella, Vibrio, Phyllobacterium, Arthrobacter, Corynebacterium, and Oceanomonas (Flores-Mireles et al. 2007; Holguin et al. 1992). Thus, they have a significant impact on the $\mathrm{N}$ cycles in coastal wetland ecosystem. In Fig.5, some rhizophere bacteria of salt marsh plants belonged to the families of Alteromonadacea, Pseudoalteromonadacea, Vibrionacea and Methylophilacea, which play key roles in the decomposition processes of dissolved organic matter. Pseudomonads are often found in contaminated aquifers, due to use a large number of substances as C sources (Moore et al., 2006).

It is well documented that $\delta$-proteobacteria is a major group of sulfur-reducing bacteria in anaerobic environments (Castro et al. 2000; Zeleke et al. 2013), which may explain higher sulfur concentrations in S. alterniflora-invaded zones as compared to with native plant and unvegetated zones (Zhou et al. 2009). In this study, after the invasion of S. alterniflora within K.obovata forest, percentage of $\gamma$-proteobacteriain rhizoplane bacteria increased, while the abundance of $\alpha$-proteobacteria in endophytic bacteria decreased. For K.obovata, $\gamma$-proteobacteria $(75.0 \pm 7.7 \%)$ 
304

305

was observed as more significant and prominent rhizoplane bacteria, followed by $\delta$-proteobacteria (7.4 $\pm 3.9 \%)$ and $\alpha$-proteobacteria (3.0 $\pm 0.4 \%)$ (Fig.4). This was consistent with the fact that $\gamma$-Proteobacteria and $\delta$-Proteobacteria were the two major classes of phylum Proteobacteria in the rhizophere of mangrove (Jiang et al. 2013). These abundant classes were clearly habitat-specific, due to the different nutrition patterns. As shown in Fig.5, some endophytic bactera in root of $S$. alterniflora were members of the order Desulfovibrionales. The genus Desulfovibrio, belonging to sulphate-reducing bacteria, is known to oxidize acetate and other organic compounds (Muyzer and Stams 2008). These species are considered as numerically important members on macrophyte root surfaces, such as Phragmites australis (Vladar et al. 2008). Desulfovibrio spp. also had strong affinity for sulphate under sulphate-limited conditions (Basso et al. 2005; Laanbroek et al. 1984) . Thus, root-associated bacteria of S. alterniflora might make a great contribution to $\mathrm{S}$ accumulation in S. alterniflora-invaded stands.

Based on analysis of microbial community, root-associated bacteria in S. alterniflora roots have the potential to affect nutrient metabolism in wetland ecosystems, especially with regard to the $\mathrm{N}$ and $\mathrm{S}$ cycles, as well as the removal of some organic matter. Variations in community structures of root-associated bacteria also provide some clues for S. alterniflora invasions. However, the culture-independent method cannot provide direct information on the function of the individual community members, therefore, further work is necessary to improve our understanding about the mechanisms through the isolation of endophytic bacteria in salt marsh plants. 
325

326

327

328

329

330

331

332

333

334

335

336

337

338

339

340

341

342

\section{Acknowledgements}

This work was supported by the National Natural Science Foundation of China (No.41006064), the Fujian Youth Science Foundation (No.2012J05081), the Natural Science Foundation of Ningbo

City (NO. 2014A610100) and the State Scholarships Foundation (No.201304910080). We also thank Professor Shen Yu from Institute of Urban Environment, CAS for his valuable comments and Dr. Yongshan Chen for collection of samples.

\section{Reference}

Alongi, D.M. 2014. Carbon cycling and storage in mangrove forests. Annual Review of Marine Science, Vol 6 6: 195-219. doi: 10.1146/annurev-marine-010213-135020.

Badri, D.V., Weir, T.L., van der Lelie, D., and Vivanco, J.M. 2009. Rhizosphere chemical dialogues: plant-microbe interactions. Current Opinion in Biotechnology 20(6): 642-650. doi: DOI 10.1016/j.copbio.2009.09.014.

Bai, S.J., Li, J.W., He, Z.L., Van Nostrand, J.D., Tian, Y., Lin, G.H., Zhou, J.Z., and Zheng, T.L. 2013. GeoChip-based analysis of the functional gene diversity and metabolic potential of soil microbial communities of mangroves. Applied Microbiology and Biotechnology 97(15): 7035-7048. doi: DOI 10.1007/s00253-012-4496-z.

Basso, O., Caumette, P., and Magot, M. 2005. Desultovibrio putealis sp nov., a novel sulfate-reducing bacterium isolated from a deep subsurface aquifer. International Journal of Systematic and Evolutionary Microbiology 55: 101-104. doi: DOI 10.1099/ijs.0.63303-0.

Berg, G., and Smalla, K. 2009. Plant species and soil type cooperatively shape the structure and function of microbial communities in the rhizosphere. Fems Microbiology Ecology 68(1): 1-13. doi: DOI 10.1111/j.1574-6941.2009.00654.x. 
347

348

Bulgarelli, D., Rott, M., Schlaeppi, K., van Themaat, E.V.L., Ahmadinejad, N., Assenza, F., Rauf, P., Huettel, B., Reinhardt, R., Schmelzer, E., Peplies, J., Gloeckner, F.O., Amann, R., Eickhorst, T., and Schulze-Lefert, P. 2012. Revealing structure and assembly cues for Arabidopsis root-inhabiting bacterial microbiota. Nature 488(7409): 91-95. doi: Doi 10.1038/Nature11336.

Blumenthal D.,Mitchell C.E., Pysek P., Jarosík V. 2009. Synergy between pathogen release and resource availability in plant invasion.Proceedings of the National Academy of Sciences of the United States of America 106(19):7899-904. doi: 10.1073/pnas.0812607106.

Caporaso, J.G., Kuczynski, J., Stombaugh, J., Bittinger, K., Bushman, F.D., Costello, E.K., Fierer, N., Pena, A.G., Goodrich, J.K., Gordon, J.I., Huttley, G.A., Kelley, S.T., Knights, D., Koenig, J.E., Ley, R.E., Lozupone, C.A., McDonald, D., Muegge, B.D., Pirrung, M., Reeder, J., Sevinsky, J.R., Tumbaugh, P.J., Walters, W.A., Widmann, J., Yatsunenko, T., Zaneveld, J., and Knight, R. 2010. QIIME allows analysis of high-throughput community sequencing data. Nat Methods 7(5): 335-336. doi: Doi 10.1038/Nmeth.F.303.

Castro, H.F., Williams, N.H., and Ogram, A. 2000. Phylogeny of sulfate-reducing bacteria. Fems Microbiology Ecology 31(1): 1-9. doi: Doi 10.1016/S0168-6496(99)00071-9.

Debbab, A., Aly, A.H., and Proksch, P. 2013. Mangrove derived fungal endophytes - a chemical and biological perception. Fungal Diversity 61(1): 1-27. doi: 10.1007/s13225-013-0243-8.

Degnan, P.H., and Ochman, H. 2012. Illumina-based analysis of microbial community diversity. Isme J 6(1): 183-194. doi: DOI 10.1038/ismej.2011.74.

Flores-Mireles, A.L., Winans, S.C., and Holguin, G. 2007. Molecular characterization of diazotrophic and denitrifying bacteria associated with mangrove roots. Applied and Environmental Microbiology 73(22): 7308-7321. doi: Doi 10.1128/Aem.01892-06. 
369

Franco Dias, A.C., Dini-Andreote, F., Taketani, R.G., Tsai, S.M., Azevedo, J.L., de Melo, I.S., and Andreote, F.D. 2011. Archaeal communities in the sediments of three contrasting mangroves. Journal of Soils and Sediments 11(8): 1466-1476. doi: 10.1007/s11368-011-0423-7.

Fuernkranz, M., Wanek, W., Richter, A., Abell, G., Rasche, F., and Sessitsch, A. 2008. Nitrogen fixation by phyllosphere bacteria associated with higher plants and their colonizing epiphytes of a tropical lowland rainforest of Costa Rica. Isme J 2(5): 561-570. doi: 10.1038/ismej.2008.14.

Gantar, M., Rowell, P., Kerby, N.W., and Sutherland, I.W. 1995. Role of extracellular polysaccharide in the colonization of wheat (Triticum Vulgare L) roots by N-2-Fixing Cyanobacteria. Biology and Fertility of Soils 19(1): 41-48. doi: Doi 10.1007/Bf00336345.

Gomes, N.C.M., Cleary, D.F.R., Pinto, F.N., Egas, C., Almeida, A., Cunha, A., Mendonca-Hagler, L.C.S., and Smalla, K. 2010. Taking Root: Enduring effect of rhizosphere bacterial colonization in mangroves. Plos One 5(11). doi: ARTN e14065DOI 10.1371/journal.pone.0014065.

Haichar, F.E., Marol, C., Berge, O., Rangel-Castro, J.I., Prosser, J.I., Balesdent, J., Heulin, T., and Achouak, W. 2008. Plant host habitat and root exudates shape soil bacterial community structure. Isme J 2(12): 1221-1230. doi: DOI 10.1038/ismej.2008.80.

Hensel, M.J.S., and Silliman, B.R. 2013. Consumer diversity across kingdoms supports multiple functions in a coastal ecosystem. Proceedings of the National Academy of Sciences of the United States of America 110(51): 20621-20626. doi: DOI 10.1073/pnas.1312317110.

Holguin, G., Guzman, M.A., and Bashan, Y. 1992. Two new Nitrogen-fixing bacteria from the rhizophere of mangrove trees: their isolation, identification and invitro interaction with rhizophere Staphylococcus sp. Fems Microbiology Ecology 101(3): 207-216.

Hong, Y., Liao, D., Chen, J., Khan, S., Su, J., and Li, H. 2015. A comprehensive study of the impact of 
391

392

394

395

polycyclic aromatic hydrocarbons (PAHs) contamination on salt marsh plants Spartina alterniflora: implication for plant-microbe interactions in phytoremediation. Environmental Science and Pollution Research 22(9): 7071-7081. doi: 10.1007/s11356-014-3912-6.

Hu, A.Y., Yang, X.Y., Chen, N.W., Hou, L.Y., Ma, Y., and Yu, C.P. 2014. Response of bacterial communities to environmental changes in a mesoscale subtropical watershed, Southeast China. Science of the Total Environment 472: 746-756. doi: DOI 10.1016/j.scitotenv.2013.11.097.

Huse, S.M., Dethlefsen, L., Huber, J.A., Welch, D.M., Relman, D.A., and Sogin, M.L. 2008. Exploring microbial diversity and taxonomy using SSU rRNA hypervariable tag sequencing. Plos Genet 4(11). doi: ARTN e1000255DOI 10.1371/journal.pgen.1000255.

Jiang, X.-T., Peng, X., Deng, G.-H., Sheng, H.-F., Wang, Y., Zhou, H.-W., and Tam, N.F.-Y. 2013. Illumina sequencing of $16 \mathrm{~S}$ rRNA tag revealed spatial variations of bacterial communities in a mangrove wetland. Microbial Ecology 66(1): 96-104. doi: 10.1007/s00248-013-0238-8.

Laanbroek, H.J., Geerligs, H.J., Sijtsma, L., and Veldkamp, H. 1984. Competition for sulfate and ethanol among Desulfobacter, Desulfobulbus, and Desulfovibrio species isolated from intertidal sediments. Applied and Environmental Microbiology 47(2): 329-334.

Lau, J.A., and Lennon, J.T. 2012. Rapid responses of soil microorganisms improve plant fitness in novel environments. Proceedings of the National Academy of Sciences of the United States of America 109(35): 14058-14062. doi: DOI 10.1073/pnas.1202319109.

Li, H., Liao, D., Su, J.Q., Huang, F.Y., and Hong, Y.W. 2014. Diversity and function of endophytic bacteria in roots of exotic plant Spartina alterniflra. Chinese Journal of Applied and Environmental Biology (in Chinese) 20(5): 856-862.

Liao, C.Z., Luo, Y.Q., Jiang, L.F., Zhou, X.H., Wu, X.W., Fang, C.M., Chen, J.K., and Li, B. 2007. 
413

414

415

416

417

418

419

420

421

422

423

424

425

426

427

428

429

430

431

432

433

434

Invasion of Spartina alterniflora enhanced ecosystem carbon and nitrogen stocks in the Yangtze Estuary,

China. Ecosystems 10(8): 1351-1361. doi: DOI 10.1007/s10021-007-9103-2.

Lovell, C.R., Piceno, Y.M., Quattro, J.M., and Bagwell, C.E. 2000. Molecular analysis of diazotroph diversity in the rhizosphere of the smooth cordgrass, Spartina alterniflora. Applied and Environmental Microbiology 66(9): 3814-3822. doi: Doi 10.1128/Aem.66.9.3814-3822.2000.

Mcleod, E., Chmura, G.L., Bouillon, S., Salm, R., Bjork, M., Duarte, C.M., Lovelock, C.E., Schlesinger, W.H., and Silliman, B.R. 2011. A blueprint for blue carbon: toward an improved understanding of the role of vegetated coastal habitats in sequestering $\mathrm{CO}_{2}$. Frontiers in Ecology and the Environment 9(10): 552-560. doi: Doi 10.1890/110004.

Mendes, R., Pizzirani-Kleiner, A.A., Araujo, W.L., and Raaijmakers, J.M. 2007. Diversity of cultivated endophytic bacteria from sugarcane: Genetic and biochemical characterization of Burkholderia cepacia complex isolates. Applied and Environmental Microbiology 73(22): 7259-7267. doi: Doi 10.1128/Aem.01222-07.

Miyamoto, T., Kawahara, M., and Minamisawa, K. 2004. Novel endophytic nitrogen-fixing clostridia from the grass Miscanthus sinensis as revealed by terminal restriction fragment length polymorphism analysis. Applied and Environmental Microbiology 70(11): 6580-6586. doi: Doi 10.1128/Aem.70.11.6580-6586.2004.

Moore, F.P., Barac, T., Borrernans, B., Oeyen, L., Vangronsveld, J., van der Lelie, D., Campbell, C.D., and Moore, E.R.B. 2006. Endophytic bacterial diversity in poplar trees growing on a BTEX-contaminated site: The characterisation of isolates with potential to enhance phytoreniediation. Systematic and Applied Microbiology 29(7): 539-556. doi: DOI 10.1016/j.syapm.2005.11.012. 
435

436

437

438

439

440

441

442

443

444

445

446

447

448

449

450

451

452

453

454

455

456

Muyzer, G., and Stams, A.J.M. 2008. The ecology and biotechnology of sulphate-reducing bacteria.

Nat Rev Microbiol 6(6): 441-454. doi: Doi 10.1038/Nrmicro1892.

Nie, M., Gao, L.X., Yan, J.H., Fu, X.H., Xiao, M., Yang, J., and Li, B. 2010. Population variation of invasive Spartina alterniflora can differentiate bacterial diversity in its rhizosphere. Plant Ecology

209(2): 219-226. doi: 10.1007/s11258-009-9687-z.

Reinhold-Hurek, B., and Hurek, T. 2011. Living inside plants: bacterial endophytes. Curr Opin Plant Biol 14(4): 435-443. doi: DOI 10.1016/j.pbi.2011.04.004.

Ringelberg, D., Foley, K., and Reynolds, C.M. 2012. Bacterial endophyte communities of two wheatgrass varieties following propagation in different growing media. Can J Microbiol 58(1): 67-80. doi: 10.1139/w11-122.

Segata, N., Izard, J., Waldron, L., Gevers, D., Miropolsky, L., Garrett, W.S., and Huttenhower, C. 2011. Metagenomic biomarker discovery and explanation. Genome Biol 12(6). doi: Artn R60Doi 10.1186/Gb-2011-12-6-R60.

Theron, J., and Cloete, T.E. 2000. Molecular techniques for determining microbial diversity and community structure in natural environments. Critical Reviews in Microbiology 26(1): 37-57. doi: $10.1080 / 10408410091154174$.

Thomas, F., Giblin, A.E., Cardon, Z.G., and Sievert, S.M. 2014. Rhizosphere heterogeneity shapes abundance and activity of sulfur-oxidizing bacteria in vegetated salt marsh sediments. Front Microbiol 5. doi: Artn 309Doi 10.3389/Fmicb.2014.00309.

Uroz, S., Buee, M., Murat, C., Frey-Klett, P., and Martin, F. 2010. Pyrosequencing reveals a contrasted bacterial diversity between oak rhizosphere and surrounding soil. Env Microbiol Rep 2(2): 281-288. 
457

458

459

460

461

462

463

464

465

466

467

468

469

470

471

472

473

474

475

476

477

478

doi: DOI 10.1111/j.1758-2229.2009.00117.x.

Vanwonterghem, I., Jensen, P.D., Ho, D.P., Batstone, D.J., and Tyson, G.W. 2014. Linking microbial

community structure, interactions and function in anaerobic digesters using new molecular techniques.

Current Opinion in Biotechnology 27: 55-64. doi: 10.1016/j.copbio.2013.11.004.

Vladar, P., Rusznyak, A., Marialigeti, K., and Borsodi, A.K. 2008. Diversity of sulfate-reducing

bacteria inhabiting the rhizosphere of Phragmites australis in lake velencei (Hungary) revealed by a combined cultivation-based and molecular approach. Microbial Ecology 56(1): 64-75. doi: DOI $10.1007 / \mathrm{s} 00248-007-9324-0$.

Wan, S.W., Qin, P., Liu, J.N., and Zhou, H.X. 2009. The positive and negative effects of exotic Spartina alterniflora in China. Ecological Engineering 35(4): 444-452. doi: DOI 10.1016/j.ecoleng.2008.05.020.

Weyens, N., van der Lelie, D., Taghavi, S., and Vangronsveld, J. 2009. Phytoremediation: plant-endophyte partnerships take the challenge Phytoremediation: plant-endophyte partnerships take the challenge. Current Opinion in Biotechnology 20(2): 248-254. doi: DOI 10.1016/j.copbio.2009.02.012.

Williams, S.L., and Grosholz, E.D. 2008. The invasive species challenge in estuarine and coastal environments: Marrying management and science. Estuar Coast 31(1): 3-20. doi: DOI $10.1007 / \mathrm{s} 12237-007-9031-6$.

Xie, W.Y., Su, J.Q., and Zhu, Y.G. 2015. Phyllosphere bacterial community of floating macrophytes in paddy soil environments as revealed by Illumina high-throughput sequencing. Applied and Environmental Microbiology 81(2): 522-532. doi: Doi 10.1128/Aem.03191-14.

Yu, Z., Yang, J., Yu, X., Liu, L., and Tian, Y. 2014. Aboveground vegetation influences belowground microeukaryotic community in a mangrove nature reserve. Wetlands 34(2): 393-401. doi: 
479

480

481

482

483

484

485

486

487

488

489

490

491

492

493

494

495

496

497

498

499

500

$10.1007 / \mathrm{s} 13157-013-0506-\mathrm{x}$.

Zeleke, J., Sheng, Q., Wang, J.-G., Huang, M.-Y., Xia, F., Wu, J.-H., and Quan, Z.-X. 2013. Effects of

Spartina alterniflora invasion on the communities of methanogens and sulfate-reducing bacteria in estuarine marsh sediments. Front Microbiol 4. doi: 10.3389/fmicb.2013.00243.

Zhang, L., and Xu, Z. 2008. Assessing bacterial diversity in soil. Journal of Soils and Sediments 8(6):

379-388. doi: 10.1007/s11368-008-0043-z.

Zhang, Q.-F., Peng, J.-J., Chen, Q., Li, X.-F., Xu, C.-Y., Yin, H.-B., and Yu, S. 2011. Impacts of Spartina alterniflora invasion on abundance and composition of ammonia oxidizers in estuarine sediment. Journal of Soils and Sediments 11(6): 1020-1031. doi: 10.1007/s11368-011-0369-9.

Zhang, Q., Peng, J., Chen, Q., Yang, X., Hong, Y., and Su, J. 2013. Abundance and composition of denitrifiers in response to Spartina alterniflora invasion in estuarine sediment. Can J Microbiol 59(12):

825-836. doi: 10.1139/cjm-2013-0516.

Zhang, Y., Huang, G., Wang, W., Chen, L., and Lin, G. 2012. Interactions between mangroves and exotic Spartina in an anthropogenically disturbed estuary in southern China. Ecology 93(3): 588-597.

Zhao, C., Liu, X., Bai, J., LuFengChun, and Li, J. 2014. Impact of Spartina alterniflora on benthic macro-invertebrates communities on mangrove wetland in Xicungang Estuary, Guangxi. Biodiversity Science 22(5): 630-639.

Zhou, C.F., An, S.Q., Deng, Z.F., Yin, D.Q., Zhi, Y.B., Sun, Z.Y., Zhao, H., Zhou, L.X., Fang, C., and Qian, C. 2009. Sulfur storage changed by exotic Spartina alterniflora in coastal saltmarshes of China. Ecological Engineering 35(4): 536-543. doi: DOI 10.1016/j.ecoleng.2008.01.004.

Zhou, H.W., Li, D.F., Tam, N.F.Y., Jiang, X.T., Zhang, H., Sheng, H.F., Qin, J., Liu, X., and Zou, F. 2011. BIPES, a cost-effective high-throughput method for assessing microbial diversity. Isme J 5(4): 
501

502

503

504

505

506

507

508

509

510

511

512

513

514

515

516

517

518

519

520

521

522

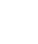

5


523 Fig. 3 PCoA analysis of bacterial community structures using the unweighted (a) and weighted (b)

524 UniFrac distances. RB: rhizoplane bacteria; EB: endophytic bacteria; SA: S. alterniflora

525 monoculture; SAM: S. alterniflora from the transition stands; RBM (EBM): Rhizoplane

526 (endophytic) bacteria in root of K. obovata monoculture; RS: Rhizopheric sediment; MS: Mudflat

527 sediment.

528 Fig. 4 Bacterial community composition in sediment, rhizoplane and endophyte of Spartina

529 alterniflora and Kandelia obovata. Minor phyla which accounting for $<0.5 \%$ of total sequences

530 are summarized in the group 'other and unclassified bacteria'. Error bars denote the standard

531 deviation.RB: rhizoplane bacteria; EB: endophytic bacteria; SA:S. alterniflora monoculture; SAM:

532 S. alterniflora from the transition stands; RBM (EBM): Rhizoplane (endophytic) bacteria in root

533 of K. obovatamonoculture; RS: Rhizopheric sediment; MS: Mudflat sediment.

534 Fig. 5 Indicator bacterial groups associated with different groups of samples identifying using

535 LEfSe algorithm (LDA > 3). EBM: endophytic bacteria in root of Kandelia obovata; EBS:

536 endophytic bacteria in root of Spartina alterniflora; RB: Rhizoplane bacteria of both plants.

537

538

539

540

541

542
Table 1 Details of different types of samples used in this study

Table 2 Estimated OTU richness and diversity indices of different type of samples collected from coastal wetland 


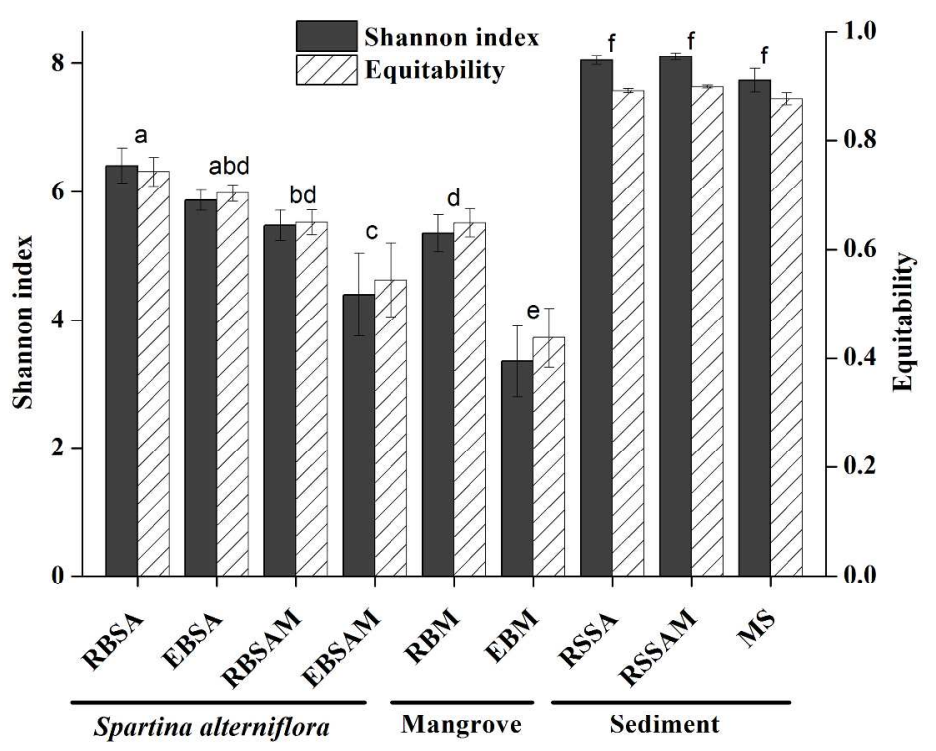

$296 \times 209 \mathrm{~mm}(300 \times 300$ DPI $)$ 


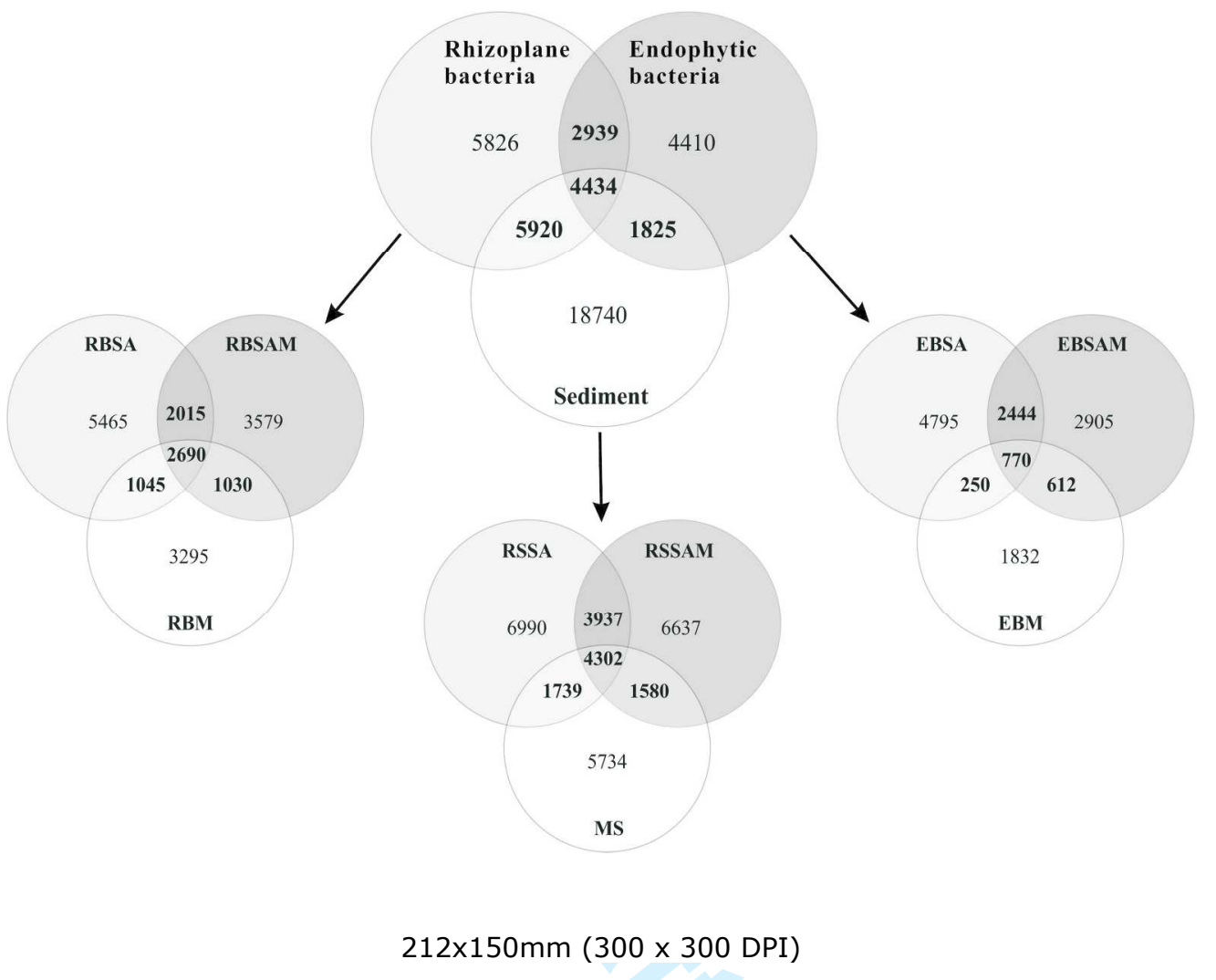



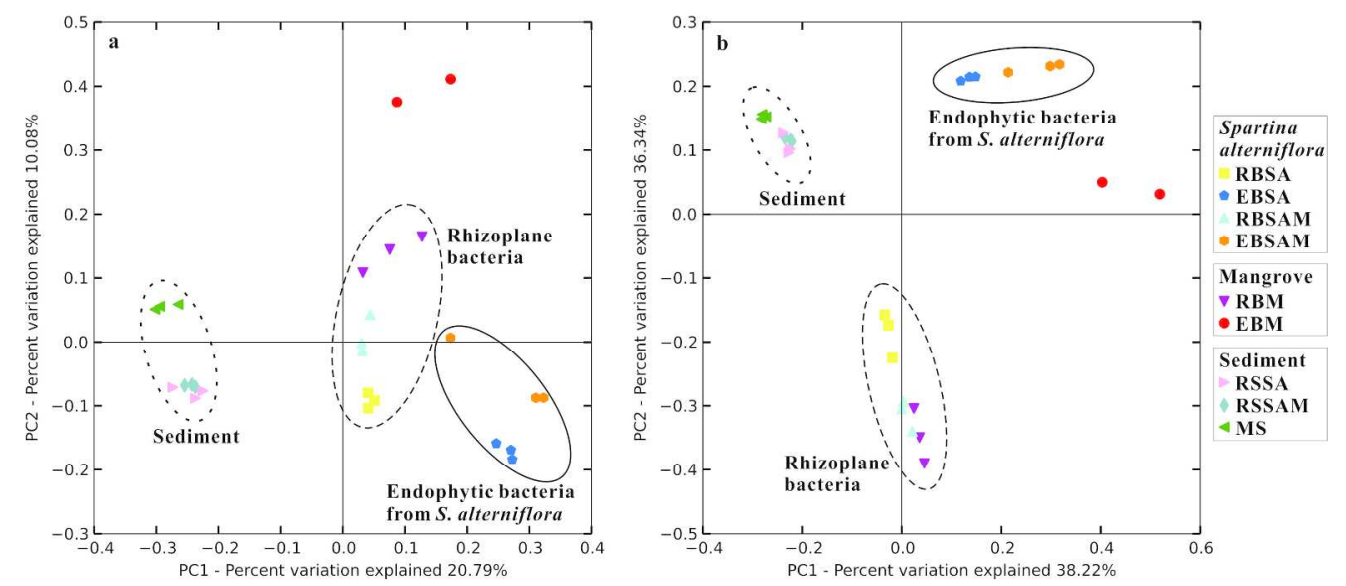

$231 \times 101 \mathrm{~mm}(300 \times 300 \mathrm{DPI})$ 


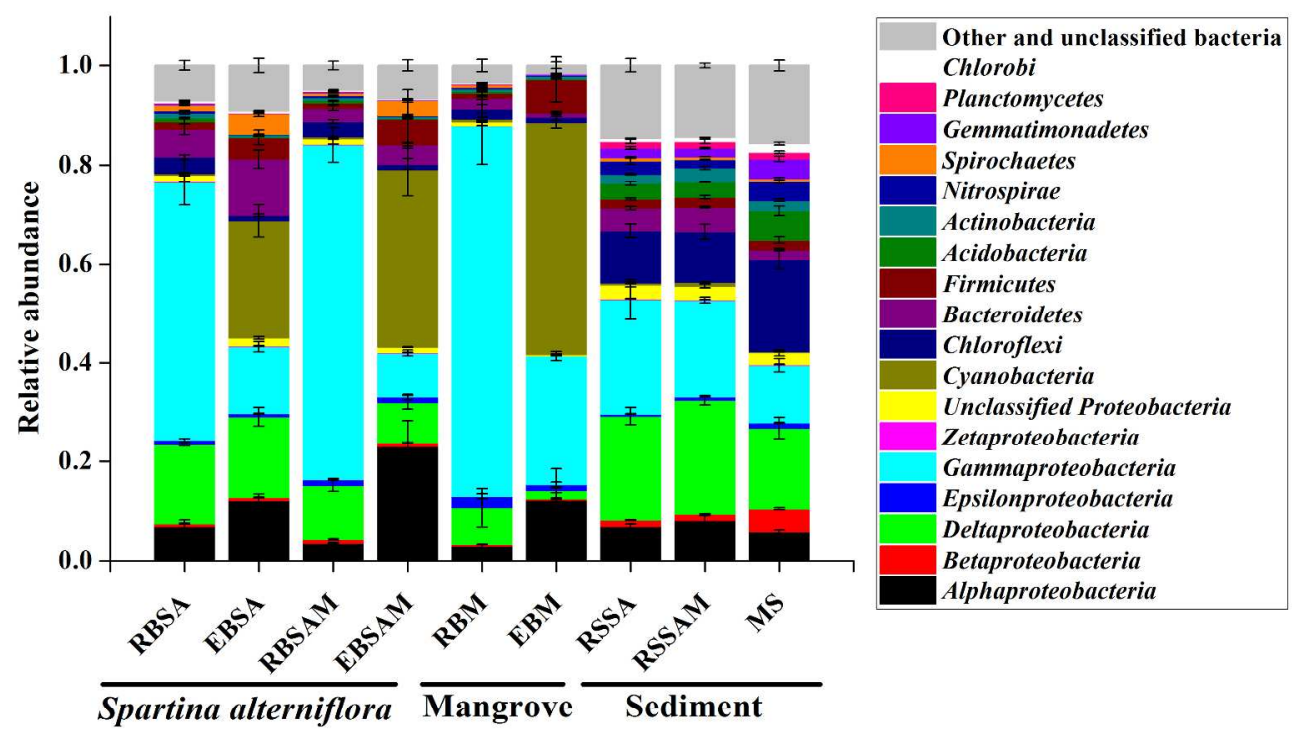

$296 \times 209 \mathrm{~mm}(300 \times 300$ DPI $)$ 


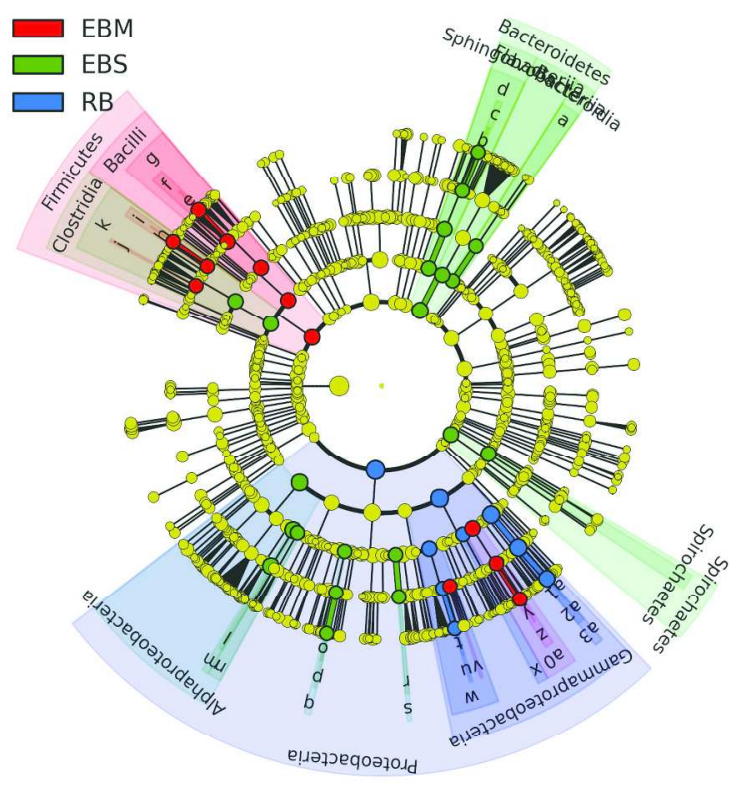

$$
\begin{aligned}
& \square \text { a: Bacteroidales } \\
& \text { b: } \text { culvivirga } \\
& \text { c: Ekhidnaceae } \\
& \text { d: Sphingobacteriales } \\
& \text { e: Paenisporosarcina } \\
& \text { f: Planococcaceae } \\
& \text { g: Bacillales } \\
& \text { h: Clostridium } \\
& \text { i: Clostridiaceae } \\
& \text { j: Peptostreptococcaceae } \\
& \text { k: Clostridiales } \\
& \text { I: mitochondria } \\
& \text { m: Rickettsiales } \\
& \text { n: Sphingomonadales } \\
& \text { o: Desulfovibrio } \\
& \text { p: Desulfovibrionaceae } \\
& \text { q: Desulfovibrionales } \\
& \text { r: JTB36 } \\
& \text { s: Sva0853 } \\
& \text { t: Ferrimonas } \\
& \text { u: Ferrimonadaceae } \\
& \text { v: Pseudoalteromonadaceae } \\
& \text { w: Alteromonadales } \\
& \text { x: Methylococcales } \\
& \text { y: Marinomonas } \\
& \text { z: Oceanospirillaceae } \\
& \text { a0: Oceanospirillales } \\
& \text { a1: Vibriu } \\
& \text { a2: Vibrionaceae } \\
& \text { a3: Vibrionales }
\end{aligned}
$$

$203 \times 152 \mathrm{~mm}(300 \times 300$ DPI $)$ 
1

2

3

4

\begin{tabular}{ccl}
\hline Types & Samples & \multicolumn{1}{c}{ Descriptions } \\
\hline Spartina & RBSA (EBSA) & Rhizoplane (endophytic) bacteria in root of S. alterniflora \\
alterniflora & & monoculture \\
& RBSAM (EBSAM) & Rhizoplane (endophytic) bacteria in root of $S$. alterniflora \\
& & from the transition stands \\
Kandelia & RBM (EBM) & Rhizoplane (endophytic) bacteria in root of $K$. obovata \\
obovata & & monoculture \\
Sediment & RSSA & Rhizopheric sediment in the $S$. alterniflora monoculture \\
& RSSAM & Rhizopheric sediment in the $S$. alterniflora from the \\
& transition stands \\
& MS & Mudflat sediment \\
&
\end{tabular}

Table 1 Details of different types of samples used in this study
5

6

7

8

9

10

11

12

13

14

15

16

17

18

19 
23 Table 2 Estimated OTU richness and diversity indices of different type of samples collected from

24 coastal wetland

\begin{tabular}{ccccc}
\hline Types & Samples & PD & Chao1 & OTUs \\
\hline Spartina altoriflora & RBSA & 333 & 14168 & 5577 \\
& EBSA & 279 & 9858 & 4213 \\
& RBSAM & 285 & 11901 & 4524 \\
Kandelia obovata & EBSAM & 232 & 7980 & 3220 \\
& RBM & 241 & 9837 & 3865 \\
Sediment & EBM & 162 & 5791 & 2142 \\
& RSSA & 453 & 20753 & 8382 \\
& RSSAM & 448 & 20280 & 8371 \\
& MS & 388 & 15337 & 6837 \\
\hline
\end{tabular}

25 All data (PD, Chao1 and OTUs) with the mean value are shown. 